\title{
Bone lengthening by physial distraction
}

\section{An experimental study}

\author{
J. de Pablos ${ }^{1}$, C. Villas and J. Cañadell \\ Department of Orthopaedic Surgery, University of Navarra, Pamplona, Spain
}

\section{SUMMARY}

Experimental physial distraction was carried out in the distal part of the femur in 45 two-month old lambs in order to study the basic mechanisms of lengthening as well as the viability of the growth cartilage after using this method. The animals were divided into three groups (A, B and C), and each group into three subgroups (1,2 and 3) according to the rate of distraction used $(2 \mathrm{~mm} /$ day, $1 \mathrm{~mm} /$ day, $0.5 \mathrm{~mm} /$ day $)$ and the time of sacrifice.

The results obtained show that the basic lengthening mechanisms consists, firstly, in the production of a fracture Between the metaphysis and the epiphysis and, secondly, that the lower the distraction speed employed, the greater is the short-term and long-term viability of the growth cartilage. Optimum viability was observed at a distraction rate of $0.5 \mathrm{~mm} /$ day.

On this basis we conclude that in clinical practice physial distraction could be indicated for children at an early stage of skeletal growth and repeated later provided that the rate of distraction is kept within reasonable limits.

\section{RÉSUMÉ}

Une étude expérimentale portant sur la distraction épiphysaire au niveau de l'extrémité distale du fémur a été réalisée chez 45 moutons âgés de 2 mois, dans le but d'étudier les mécanismes d'allongement ainsi que la vitalité du cartilage de croissance. Les animaux ont été divisés en trois groupes $(\mathrm{A}, \mathrm{B}, \mathrm{C})$ et 9 sous-groupes $(1,2,3)$ selon la vitesse de l'allongement ( $2 \mathrm{~mm} /$ jour, $1 \mathrm{~mm}, 0,5 \mathrm{~mm})$ et la date à laquelle ils ont été sacrifiés.

Les résultats obtenus montrent que le mécanisme de base consiste dans la création d'une fracture épiphysodiaphysaire et, d'autre part, que plus la vitesse d'élongation est lente, plus le cartilage de croissance est viable à court et à long terme. Les meilleurs résultats furent obtenus à la vitesse de $0,5 \mathrm{~mm} / \mathrm{jour}$. On peut donc conclure qu'en pratique la distraction épiphysaire peut être indiquée chez les enfants dont l'âge osseux est bas, et qu'elle peut être répétée ultérieurement, à condition de maintenir la vitesse d'allongement dans des limites raisonnables.

\section{KEY WORDS}

Physial distraction, Bone lengthening 


\section{INTRODUCTION}

Physial distraction is a procedure originally designed and used to obtain bone lengthening. The first experiments based on this concept were published by Ring in 1958 [25] who described physial distraction in dogs using small external distractors. Other authors subsequently reported experimental studies designed to resolve the many doubts which had arisen concerning this procedure $[7,8,9,11,12,13,14,18,19]$.

These techniques were first applied clinically with notable success in Eastern Europe. Publications by Zavijalov and Plaskin appeared in 1967 [30] and 1968 [31], Ilizarov and Soybelman in 1969 [10], and later by others [De Bastiani pers. comm. 1983, 2, 3, 4, 5, $6,9,16,17,20,24,29,31]$.

The most outstanding advantages of physial distraction over other methods of bone lengthening which are at present in use can be summed up thus:

1. The application is simple and rapid.

2. A single stage operation only is needed.

3. No surgical division of skin, periosteum or bone is required.

4. No bone graft or internal fixation devices are used.

As well as problems which are common to other methods using mechanical distraction, such as the effect of distraction on joint cartilage and soft tissues, there are certain doubts specifically related to physial distraction, among which the following are perhaps the most outstanding.

1) The basic mechanism directly responsible for bone lengthening by means of physial distraction. While most authors believe that lengthening through physial distraction is produced by transverse physial fracture ("locus minor resistentiae") $[10,30,31]$, others $[21,22,27]$ hold that it is accomplished by stimulation of the growth cartilage without the need for fracture.

2) Long-term functional and morphological viability of the growth cartilage at the point where distraction is performed. This, in our opinion, is a question of crucial importance, particularly with regard to the clinical application of this method in young patients. There has been a wide divergence of opinion on this issue $[7,8,9$, $18,19,20,21,23,25,27]$.

Our experimental study was carried out in an effort to answer these questions.

\section{MATERIAL AND METHODS}

The study was made on 45 two-month-old Merino lambs (ovis aries), 40 males and 5 females, weighing between 13 and 15 kilogrammes. Skeletal maturity is reached in this breed at approximately 8 months.

The distraction device employed was an experimental prototype of the Dynamic Axial Fixator (DAF) Orthofix ${ }^{\circledR}$ [1] using self-tapping screws with conical threads. Distraction was always applied to the distal physial plate of the left femur, with the contralateral femur as control. The insertion of the screws, 2 epiphysial and 2 diaphysial screws aligned in two perpendicular planes, was always made in an experimental operating 
room on anaesthetized animals under radiographic control. A radiograph was taken after each intervention to ensure parallelism between the distractor and the longitudinal axis of the bone, as well as satisfactory screw placement. Distraction was begun $36 \mathrm{~h}$ after operation, twice daily, at $12 \mathrm{~h}$ intervals, until $2 \mathrm{~cm}$ of lengthening was reached. Once the desired lengthening was obtained, the telescoped distractor mechanism was locked, and the apparatus was removed 45 days later.

The 45 lambs were divided into three groups of 15 each according to the distraction speed employed (Table 1). Each group was further divided into subgroups of 3 (1, 2 and 3 ) depending on the time of sacrifice, which was on conclusion of lengthening (subgroup 1), $1^{1 / 2}$ months after distraction was finished (subgroup 2), and at 6 months of age, that is, 4 months after distraction began (subgroup 3).

The results were assessed as follows:

1. Radiographs of the lengthened femur were taken in the antero-posterior projection immediately after operation, and of both femora in antero-posterior and lateral projections immediately following sacrifice.

2. Specimen measurement: measurements were made of both femora and both tibiae of all lambs at the immediate post-operative and intermediate stages, i..e. at the end of lengthening, 45 days following the end of lengthening, and at 6 months of age, according to the life span planned for each lamb.

3. Histological study: this was made at the level of the distal extremity of both femora of each lamb, using Haematoxyline-Eosin and Masson's trichromic stains.

\section{RESULTS}

\section{Radiological study}

Precisely at the end of lengthening (subgroups $A_{1}, B_{1}, C_{1}$,) we observed a radiolucent area, the lengthened zone, between the epiphysis and metaphysis. This area showed hardly any signs of calcification (Fig. $1 \mathrm{~A}$ ) in subgroup $\mathrm{A}_{1}$ at 10 days. In subgroup $\mathrm{B}_{1}$ (20 days) there was already a partially calcified area at the periphery with a more radiolucent central area (Fig. 1 B). In group $C_{1}$ (40 days) this was even more obvious (Fig. $1 \mathrm{C}$ ). At 45 days after the end of lengthening, gradual reconstruction of the lengthened zone, spreading from the periphery to the central area, could be observed in subgroups $\mathrm{A}_{2}$ (Fig. 2A) and $\mathrm{B}_{2}$ (Fig. 2B). In subgroup $\mathrm{C}_{2}$ (Fig. 2C), 85 days after the beginning of distraction, there was total calcification of the lengthened zone which was without a radiolucent central area.

At 6 months of age, 4 months after the beginning of distraction, advanced reconstruction was observed in the lengthened zone in subgroups $A_{3}, B_{3}$ and $C_{3}$. The lengthened zone showed calcification in all three subgroups and, although differences were minimal, fine trabeculation could be detected in this area in femora which were lengthened more slowly (subgroup C3). This seems to indicate better reconstruction of the lengthened zone in these animals. 


\section{Specimen measurement}

Although all the specimens of the femur and tibia were measured, we will refer here only to the comparative study of femoral discrepancies noted in those subgroups with the longest time span scheduled $\left(\mathrm{A}_{3}, \mathrm{~B}_{3}\right.$ and $\left.\mathrm{C}_{3}\right)$, which we considered to be more relevant. All the values are cited as mean figures for greater simplicity (Fig. 3).

At the start, similar discrepancies were obtained in the three subgroups $\left(\mathrm{A}_{3}: 2.06 \pm 0.11\right.$ $\mathrm{cm} ; \mathrm{B}_{3}: 2.02 \pm 0.19 \mathrm{~cm}$ and $\mathrm{C}_{3}: 1.88 \pm 0.15 \mathrm{~cm}$ ) though at different times, seemingly owing to the different lengthening speeds employed in each group.

Forty-five days after lengthening ceased, a decrease in the discrepancy was observed in the three subgroups $\left(\mathrm{A}_{3}: 1.48 \pm 0.13 \mathrm{~cm} ; \mathrm{B}_{3}: 1.40 \pm 0.10 \mathrm{~cm}\right.$ and $\left.\mathrm{C}_{3}: 1.45 \pm 0.13 \mathrm{~cm}\right)$. This is because the growth of the distracted femur at the distal physeal level was completely stopped by the locked distractor, while the control femur was growing normally.

Lastly, 4 months after lengthening had begun, greater differences in the mean discrepancies were seen in the different subgroups, a pronounced drop for subgroup $\mathrm{A}_{3}$ $(0.96 \pm 0.05 \mathrm{~cm})$, a lesser but evident drop in subgroup $\mathrm{B}_{3}(1.22 \pm 0.18 \mathrm{~cm})$, and a constant discrepancy, always with respect to the earlier control, in subgroup $\mathrm{C}_{3}(1.43 \pm$ $0.10 \mathrm{~cm})$.

There is no doubt that the discrepancy obtained by distraction was better maintained in those femora in which lengthening had occurred more slowly.

\section{Histological study}

The morphological changes observed in the lengthened zone immediately after distraction ceased (subgroups $A_{1}, B_{1}$ and $C_{1}$ ) confirmed that in every case there was a local fracture between the metaphysis and the epiphysis with a gap the lengthened zone, in an advancing state of reconstruction (Figs. 4A and B). The fracture line was quite easily visible in subgroup $A_{1}$ specimens. The distal area (Fig. 4B) corresponded to the degenerate layer of growth cartilage, while the proximal area corresponded to the calcified stratum which remained joined to the distal femoral metaphysis. Nevertheless, in subgroup $B_{1}$ and particularly in subgroup $C_{1}$, a repair process had already begun which made it difficult to recognise the exact site of the fracture.

Morphological changes observed in the physis of the lengthened side as compared to the control side increased in direct proportion to the rate of lengthening. In subgroup $\mathrm{A}_{1}$ (Fig. 5 A) the growth cartilage was in contact with the epiphysial bone for almost all its thickness. This cartilage showed conspicuous thinning of the germinal layer which was in marked contrast to the appearance of the control. It was mostly composed of hypertrophic and degenerative cells with an almost total absence of proliferative stratum cells. The thickening of the hypertrophic and degenerative layers gave the physial plate on the lengthened side a uniformly widened appearance compared to that of the control. Likewise, on the lengthened side, frequent longitudinal cracks were to be seen running through the growth cartilage, and these were filled with a haematic tissue, similar to the haematoma occupying the lengthened zone in these specimens (Fig. 5 B). 
In subgroup $A_{2}$ we observed striking deterioration of the distal physis in all of the lengthened femora. In contrast to the control side, there was conspicuous thinning of the germinal zone with disorganization present in the remaining layers and frequent longitudinal fissures.

In subgroup $A_{3}$ (Fig. 5C, D), small bony bridges were seen occasionally to interrupt the growth cartilage on the lengthened side in such a way as to establish communication between the bone formed in the lengthened zone and the epiphysis.

In subgroup $B_{1}$, the growth cartilage retained an almost normal structure although there were many longitudinal cracks filled with fibrous tissue. The thinning of the germinal layer compared to that of the control side was also noteworthy.

In subgroup $B_{3}$, the growth cartilage on the lengthened side showed marked thinning of the germinal layer compared to the control. The remaining cartilage layers showed a more satisfactory structure than that observed in subgroup $A_{3}$. There were also many interruptions of bone trabeculae.

In the group $\mathrm{C}$ subgroups, comparison of the growth cartilage of the control and lengthened sides showed few morphological changes. Specifically, in subgroup $\mathrm{C}_{1}$ (Fig, 6 A, B) occasional and discrete structural disintegration was present in the calcified layer which formed part of the metaphysial side, as previously mentioned. Within the cartilage close to the epiphysis there was a generally well conserved structure, which showed slight thinning of the germinal layer. In subgroup $\mathrm{C}_{2}$ differences were minimal, and in $\mathrm{C}_{3}$ (Fig. 6C and D) the growth cartilage on both control and lengthened sides appeared the same.

The lengthened zone was first wholly occupied by a haematoma (Fig. 7 A) which quickly coagulated and began to organize at the periphery after 10 days of lengthening. In only a few days the haematic tissue gave way to a rich, granulation tissue (Fig. 7 B) composed of numerous fibrous cells and collagen fibres, which proceeded to align themselves parallel to the traction and to condense sporadically. This produced a macroscopic appearance of longitudinal striation. Throughout this process the walls of the lengthened zone, which consisted of a thin membrane of compact fibrillary collagen, always remained intact with the lateral borders clearly defined.

Peripheral ossification of the lengthened zone was first observed on the 20th day of lengthening. This is a desmal ossification (Fig. 7 C), except for the normal enchondral ossification taking place in the growth cartilage at the level of the calcified stratum. This ossification progressively replaced the fibrous granulation tissue with bone-tissue, occurring simultaneously from the epiphysis and metaphysis as well as from the walls of the lengthened zone in which normal periosteal ossification could also be observed.

Four months after the lengthening process had begun, practically all the tissue in the lengthened zone showed complete ossification, regardless of the rate at which distraction had been applied. Although the differences were admittedly slight, we attach special significance to the more advanced stage of development found in subgroup $\mathrm{C}_{3}$, in which specimens were lengthened more slowly, where there was greater trabecular density and more mature cortical bone compared to specimens from subgroups $\mathrm{A}_{3}$ and $\mathrm{B}_{3}$, which had been subjected to more rapid distraction. 


\section{DISCUSSION}

Most authors who have performed this technique of bone lengthening, whether experimentally $[7,8,9,11-15,18,19]$ or clinically $[2,3,6,10,15,17,19,20,24,30$, 31], share our opinion that physial distraction is a method of proven effectiveness for obtaining lengthening.

We likewise agree with the opinion of most authors that the basic mechanism involved in producing bone lengthening by this method consists in the production of an initial fracture, followed by progressive separation of the epiphysis and metaphysis, when accompanied by the continuous application of distraction forces $[7,8,9,10,12,13,14$, $17,19,20,25,30,31,33]$. We found no signs which indicated a stimulation of physial plate activity [De Bastiani, pers. comm. 1983, 21, 22, 27] nor physial plastic deformities [De Bastiani, pers. comm. 1983] as mentioned by some authors. We did observe the appearance of a global widening of the physis on the lengthened side with respect to the control side in subgroup $A_{1}$, due to an increase of cellularity in the hypertrophic and degenerative layers. These changes, observed also by Sledge and Noble [27], are explained by these authors as a response to the stimulus induced by traction forces affecting growth cartilage activity. However, we consider essential the role played by ischaemia on the metaphysial side of the growth cartilage $[26,28]$ following physial fracture as observed in our cases. This ischaemia would produce an increase of cellularity in the degenerative and hypertrophic layers, until new vessels penetrated into the area to replace the degenerated cartilage with bone tissue. Most authors also agree that there is a transverse physial fracture, the line of which is localised between the degenerative and calcified layers $[7,8,10,17,19,20,25,30,31]$.

In our study, fractures were observed in all cases, regardless of the rate of distraction, although we were only able to trace the fracture line clearly in subgroup $A_{1}$. In subgroups $B_{1}$ and $C_{1}$ a repair process was already in progress by the time lengthening was concluded. The fracture line observed in subgroup $A_{1}$ was localised between the degenerative and calcified layers of the growth cartilage.

We basically agreed with sequences of radiological evolution recorded by others [12, $13,18]$, but radiographic evidence of reconstruction was almost complete in all cases at 4 months from the beginning of distraction. Although we observed, as did other authors [18], differences in the rate of reconstruction which were related to the rate of distraction, these differences were quite small and consequently they cannot, in our opinion, be considered of great significance.

In the histological evolution of the lengthened zone we observed, as did other authors $[7,8,18]$, the following sequence. Physial fracture haematoma was formed first and was then substituted by fibrous granulation tissue. Desmal ossification of fibrous tissue then occurred with reconstruction of the periosteal bone. This sequence was repeated in all the cases studied regardless of the speed of lengthening, but perfection of reconstruction was associated with a lower rate of distraction. However, these differences were, as in the radiological study, only slight so we do not consider them to be of any special significance.

The most debatable findings concerned the histological changes in the growth cartilage on the lengthened side. The possibility of damaging the growth cartilage through the 
application of traction forces was already a question which concerned Ring in 1958 [25], when he found premature fusion in the physis on the lengthened side. This was subsequently confirmed by other experimental studies [7, 8, 12, 13, 14]. Monticelli [15, $17,18]$ produced sudden physial fractures ("distractional epiphysiolysis") in lamb tibiae and observed cases in which the physis on the lengthened side showed distortion of the proliferative layer, as well as an overall disorganization, while in other cases the cartilage on both control and lengthened sides showed close similarities. Such uncertainty about the future consequences which this method of lengthening might have upon the growth cartilage has limited its use in general to children near skeletal maturity $[2,10,16,17,20,29]$.

In our experiments, we observed how the morphology of the growth cartilage varied clearly in direct relation to the speed of lengthening employed. Thus, in those femora in which lengthening took place at a daily rate of $0.5 \mathrm{~mm}$, the growth cartilage remained essentially normal in all the phases studied. However, in femora lengthened at a rate of $1 \mathrm{~mm} /$ day, and especially at $2 \mathrm{~mm} /$ day, obvious lesions were observed, particularly in those studied 45 days following the conclusion of lengthening and at 6 months of age. These morphological findings were later confirmed by the evolutional study of the discrepancies obtained. The slower the rate of distraction, the better was the long-term maintenance of the discrepancy. We conclude that the fundamental factors on which the viability of the growth cartilage in physial distraction depend are the suddenness with which fracture is produced as well as the rate of distraction used.

On the basis of our results, and in relation to the clinical implications of this experimental study, we conclude that this method makes it possible to obtain lengthening without risk of damage to the growth cartilage or impairment of its function, provided that the speed of lengthening is maintained within reasonable limits. Consequently physial distraction could be used at an early skeletal age and repeated if necessary at a later stage of growth.

\section{ACKNOWLEDGEMENTS}

The authors wish to thank Dr. G. de Bastiani, Dr. R. Aldegheri and Dr. L. Renzi-Brivio from the Department of Orthopaedic Surgery, University of Verona, Verona, Italy for their continuous support in this experimental project.

\section{REFERENCES}

1. De Bastiani G, Aldegheri R, Renzi Brivio (1984) The treatment of fractures with a dynamic axial fixator. J Bone Joint Surg 66-B: 538-545

2. Bensahel H, Hugerin Ph, Biard JL (1983) L'allongement trans-épiphysaire du tibia. A propos d'un cas. Rev Chir Orthop 69: 245-247

3. Berchiche R, Wittek F (1983) Allongement du squelette jambier par épiphysiolyse-distraction. Traitement des inégalités des membres inférieurs. Acta Orthop Belg 49: 321-313

4. Eydelshtein BM, Udalova NI, Bochkarev GF (1973) Dynamics of reparative regeneration after lengthening by the method of distraction epiphysiolysis. Acta Chir Plast 15: 149-154 
5. Fischenko PJ, Sadovefa VI, Karimova LF, Pilipenko NP (1976) Roentgenographic imaging of the regenerate formation in distraction epiphysiolysis. Ortop Traumatol Protez 37: 29-41

6. Fischenko PJ, Karimova LF, Pilipenko NP (1976) Distraction epiphysiolysis in congenital shortening of lower extremities. Ortop Traumatol Protez 37: 44-62

7. Fishbane BM, Riley LH (1976) Continuous trans-physeal traction. A simple method of bone lengthening. Johns Hopkins Med J 138: 79-81

8. Fishbane BM, Riley LH (1978) Continuous transphyseal traction: Experimental observation. Clin Orthop 136: 120-124

9. Houghton GR, Duriez J (1980) Allongement tibial par élongation du cartilage de croissance tibial supérieur. Etude expérimentale chez le lapin. Rev Chir Orthop 66: 351-356

10. Ilizarov GA, Soybelman LM (1969) Some clinical and experimental data on the bloodless lengthening of lower limbs. Exp Khir Anes 4: 27-32

11. Ilizarov GA, Soybelman LM, Chirkova AM (1970) Some roentgenologic and morphological data on regeneration of bone tissue in experimental distraction epiphysiolysis. Ortop Traumatol Protez 31: 26-45

12. Jani L (1973) Tierexperimentelle Studie über Tibia-verlängerung durch Distraktionepiphyseolyse. Z Orthop 111: 627-630

13. Jani L (1975) Die Distraktionepiphyseolyse. Tierexperimentelle Studie zum Problem der Beinverlängerung. Z Orthop 113: 189-198

14. Letts RM, Meadows L (1978) Epiphysiolysis as a method of limb lengthening. Clin Orthop (Rel Res) 133: 230-245

15. Monticelli G, Spinelli R (1979) Personal communication. Giornate Italiane del Fiassatore Esterno. Venice (Italy), 1979).

16. Monticelli G, Spinelli R (1981) Allongement des membres par distraction épiphysaire. Rev Chir Orthop 67: 215-220

17. Monticelli G, Spinelli R (1981) Limb lengthening by epiphyseal distraction. Int Orthop (SICOT) 5: 85-90

18. Monticelli G, Spinelli R (1981) Distraction epiphysiolysis as a method of limb lengthening. I. Experimental study. Clin Orthop Rel Res 154: 256-261

19. Monticelli G, Spinelli R, Bonucci E (1981) Distraction epiphysiolysis as a method of limb lengthening. II. Morphologic investigations. Clin Orthop Rel Res 154: 262-273

20. Monticelli G, Spinelli R (1981) Distraction epiphysiolysis as a method of limb lengthening. III. Clinical applications. Clin Orthop Rel Res 154: 274-285

21. Noble J, Sledge CB, Walker PS, Diamond R, Stirratt CR, Sosman JL (1978) Limb lengthening by epiphysial distraction. J Bone Joint Surg 60-B: 139-140

22. Noble J, Diamond R, Stirratt CR, Sledge CB (1982) Breaking force of the rabbit growth plate and its application to epiphyseal distraction. Acta Orthop Scand 53: $13-16$

23. Ogden JA (1982) Skeletal injury in the child. Ed Lea \& Febiger. Philadelphia, pp 59-60

24. Ricciardi L (1984) Epifisiolisi distrazionale monocompartimentale. G Ital Ortop Traum 10: 57-61

25. Ring PA (1958) Experimental bone lengthening by epiphyseal distraction. Br J Surg 49: 169-173

26. Salter RB, Harris WR (1969) Injuries to the growth plate. In "The growth plate and its disorders". Mercer Rang. Ed Williams and Wilkins, Baltimore p 133 
27. Sledge CB, Noble J (1978) Experimental limb lengthening by epiphyseal distraction. Clin Orthop Rel Res 136: 111-119

28. Trueta J, Amato VP (1960) The vascular contribution to osteogenesis. III. Changes in the growth cartilage caused by experimentaly induced ischaemia. $\mathbf{J}$ Bone Joint Surg 42-B: 571-597

29. Wevdenskogo SP (1974) Distraction epiphysiolysis of crural bones. Ortop Traumatol Protez 10: 53-55

30. Zavijalov PV, Plaskin JT (1967) Elongation of crural bones in children using a method of distraction epiphysiolysis. Vest Khri Grekova 103: 67-82

31. Zavijalov PV, Plaskin JT (1968) Distraction epiphysiolysis in lengthening of the lower extremity in children. Khirurgija 44: 121-137 


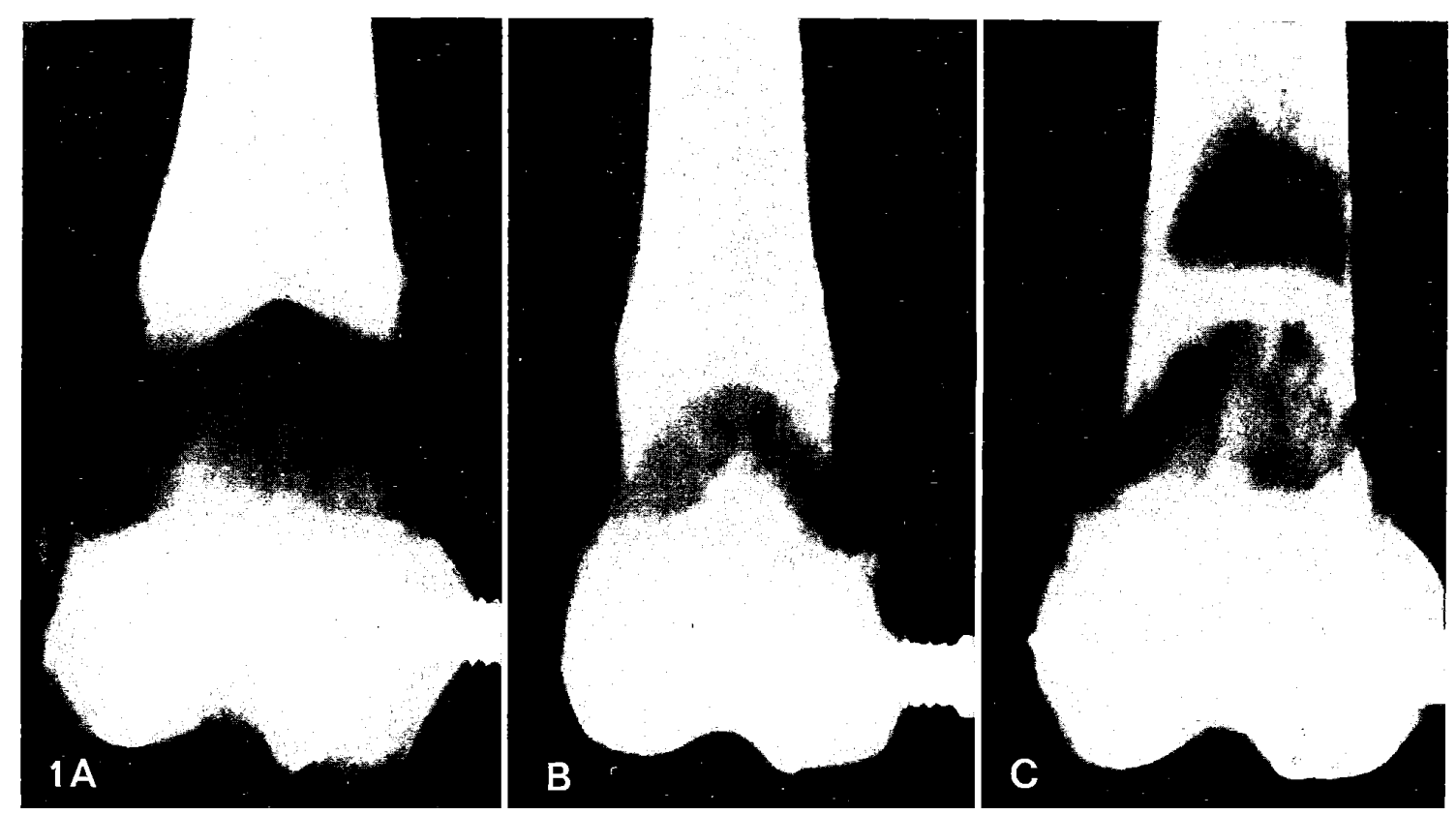

Figure 1. Radiographs A Subgroup $A_{1}$, B Subgroup $B_{1}$ C Subgroup $C_{1}$

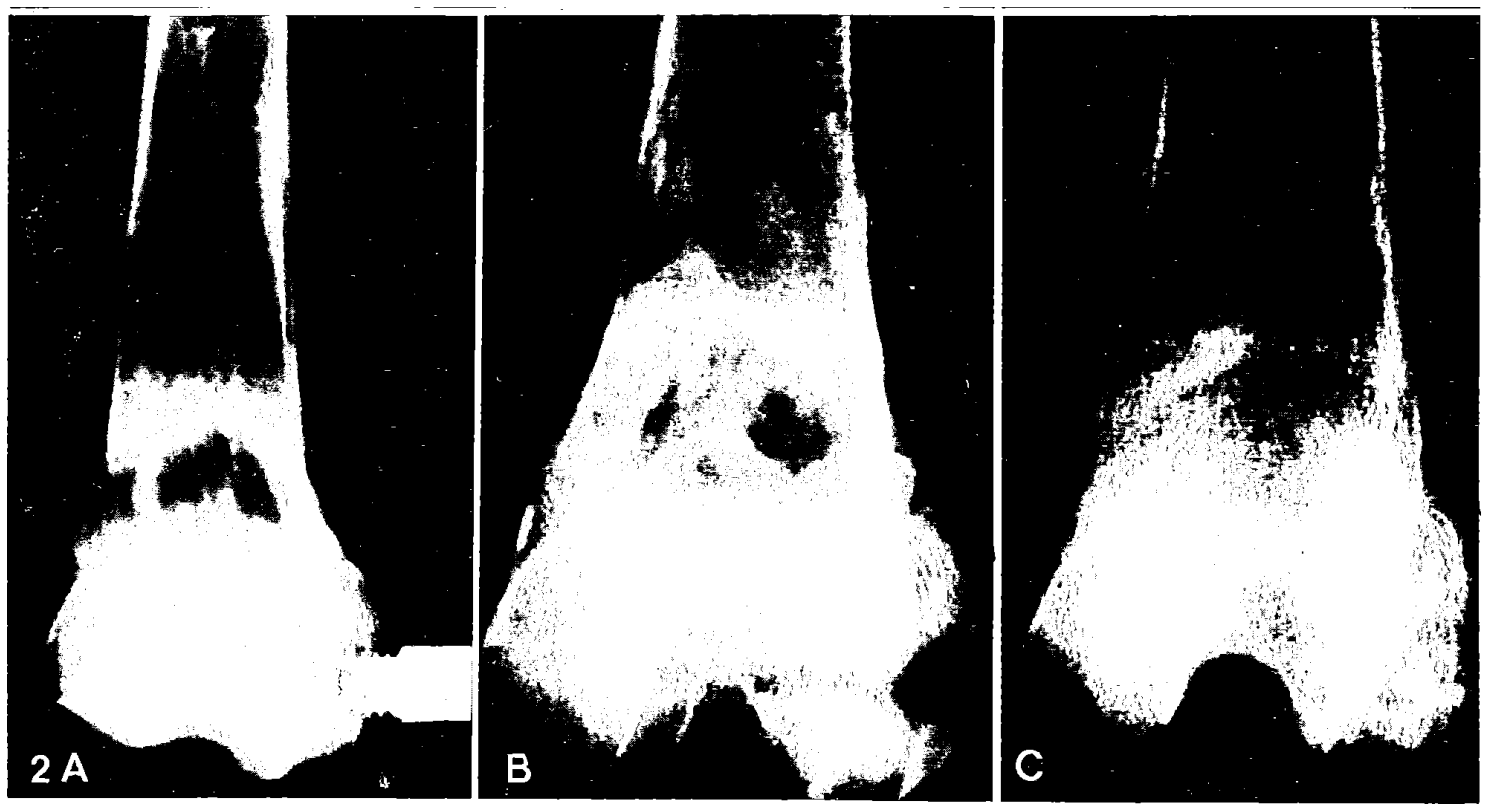

Figure 2. A Subgroup $A_{2}$, B Subgroup $B_{2}$ C Subgroup $C_{2}$ 


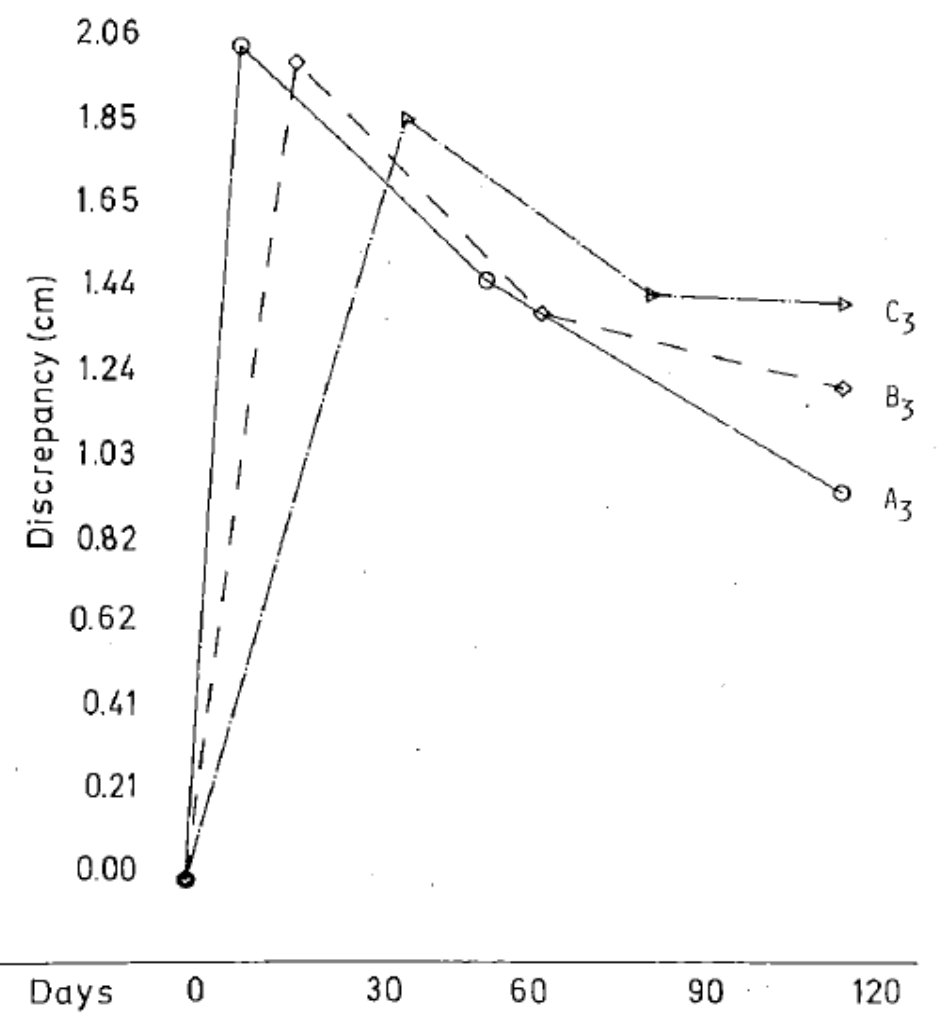

Figure 3. Graph showing the evolution of the discrepancies in subgroups $A_{3}, B_{3}$ and $C_{3}$
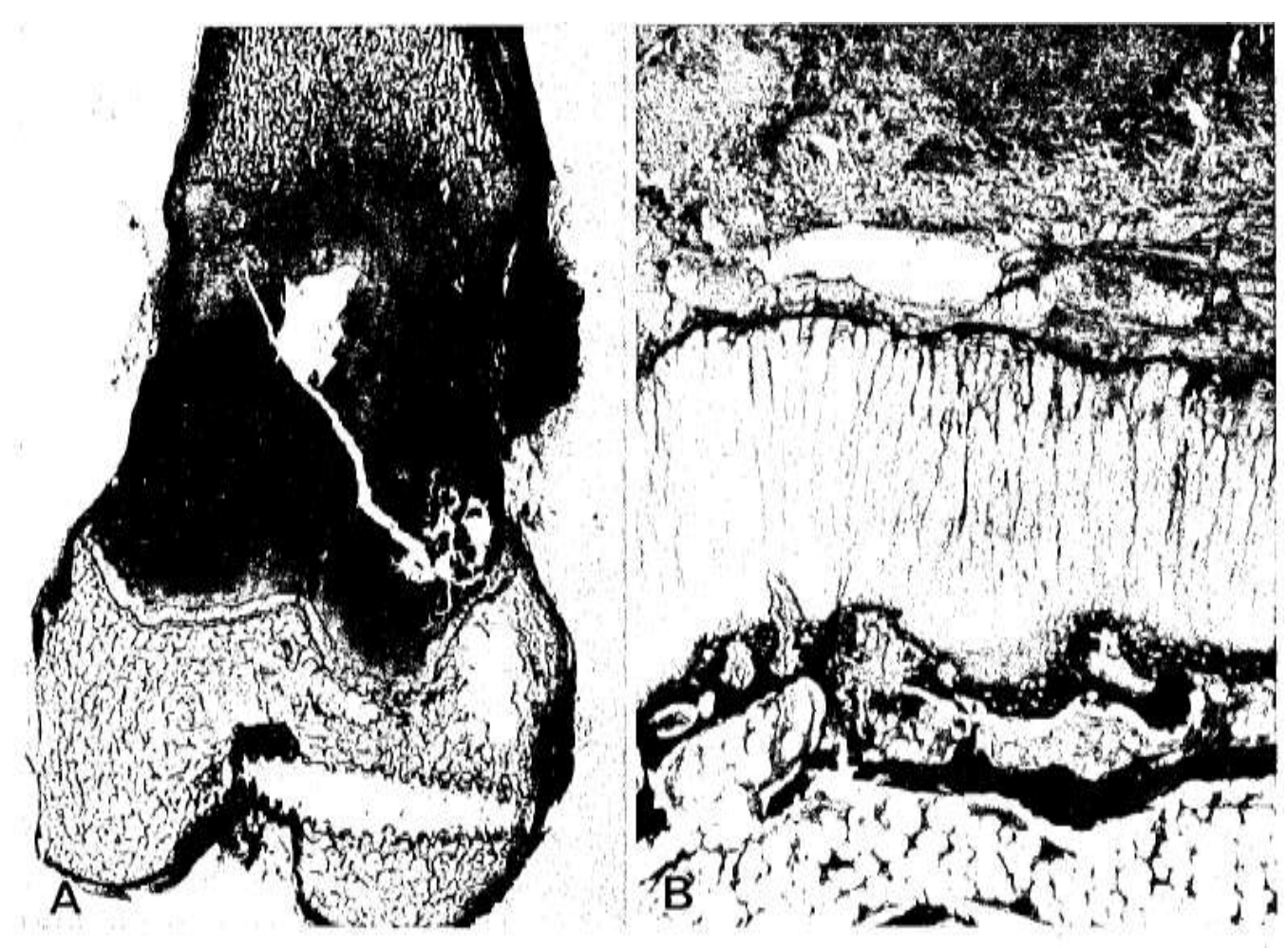

Figure 4. Histology. Subgroup $A_{1}$ using Massons's trichromic stain. A Macroscopic specimen. B Microscopic specimen 


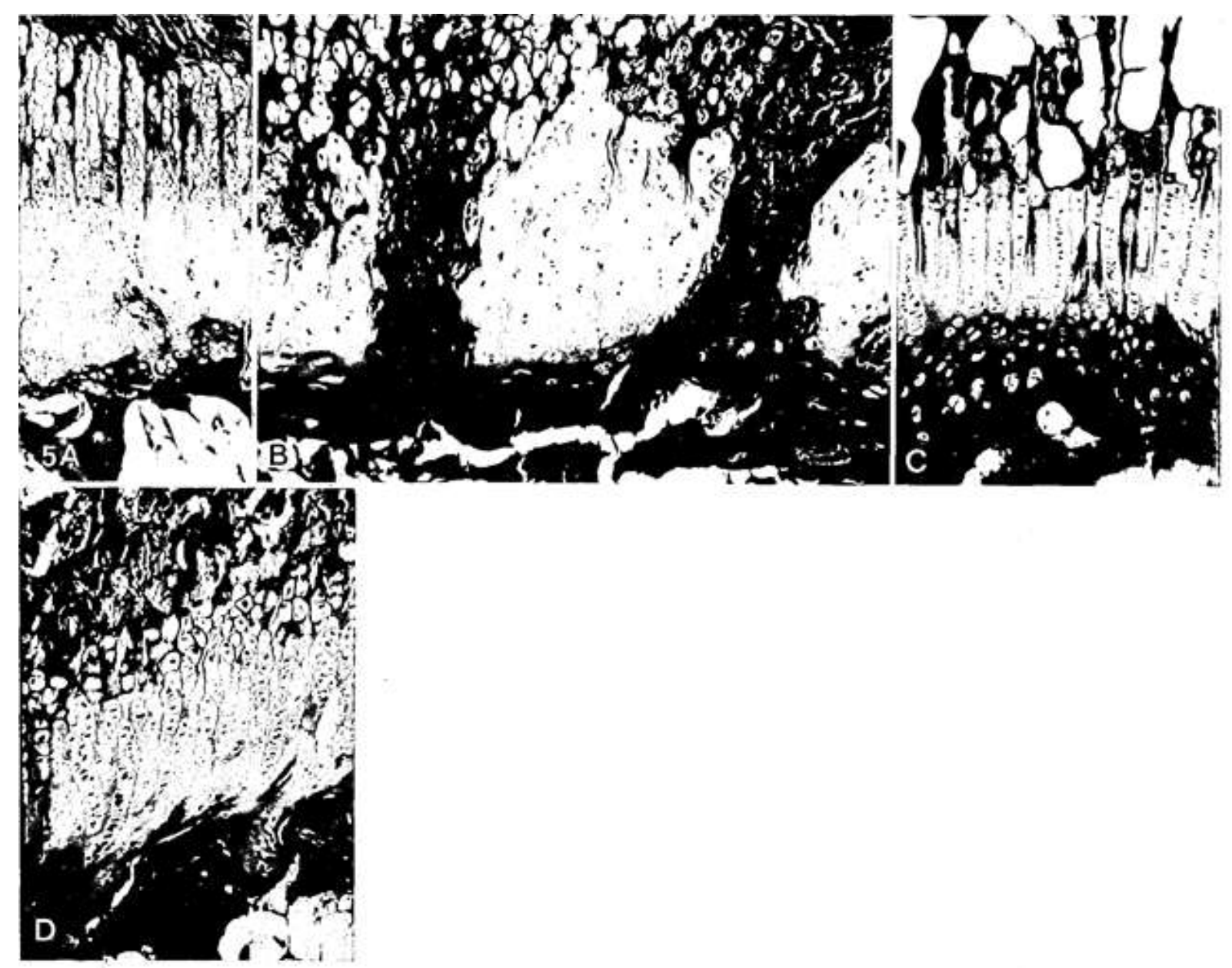

Figure 5. Histology of growth cartilage in Group A using Masson's trichromic stain ( x 10). A Subgroup $A_{1}$ - lengthened side. B Subgroup $A_{1}$ - lengthened side showing longitudinal fissures. C Subgroup $A_{3}$ - control side. D Subgroup $A_{3}$ - lengthened side

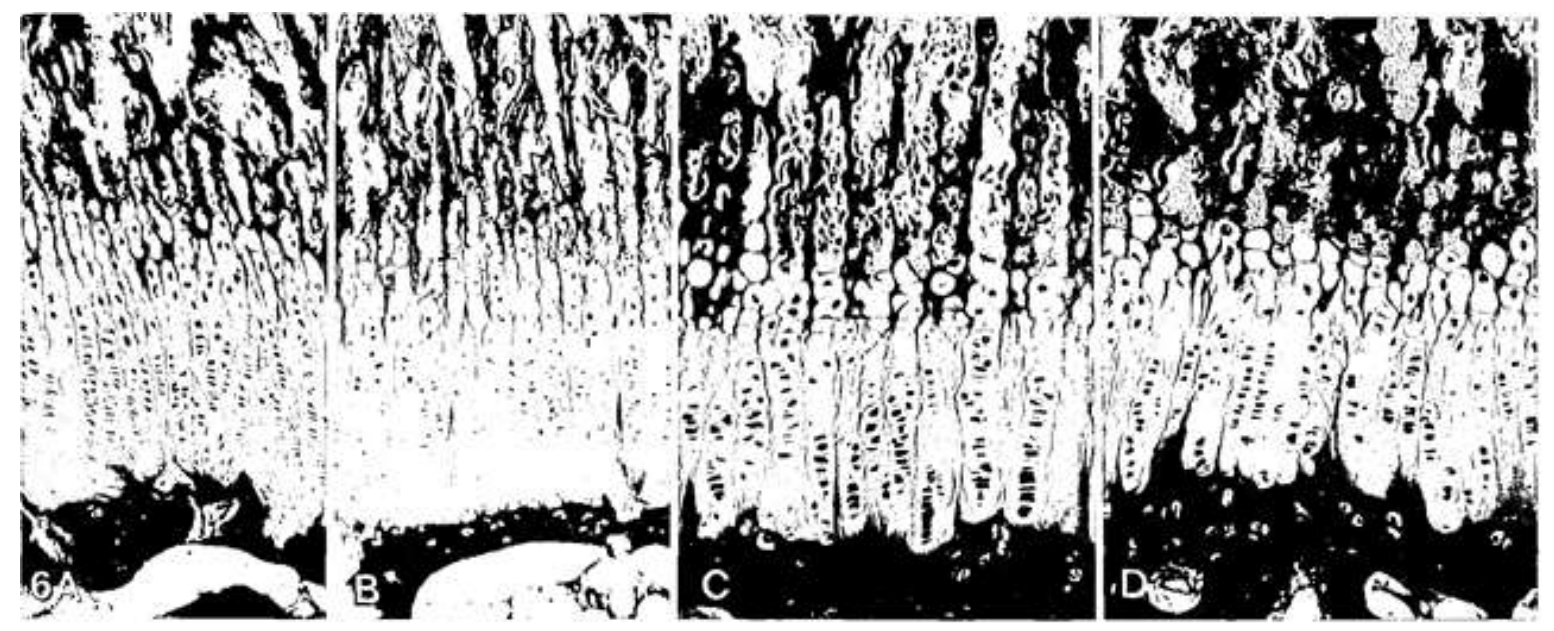

Figure 6. Histology of growth cartilage in Group $\mathrm{C}$ using Masson's trichromic stain ( $x$ 10). A Subgroup $\mathrm{C}_{1}-$ control side. B Subgroup $\mathrm{C}_{1}-$ lengthened side. C Subgroup $\mathrm{C}_{3}$ - control side. D Subgroup $\mathrm{C}_{3}$ - lengthened side 


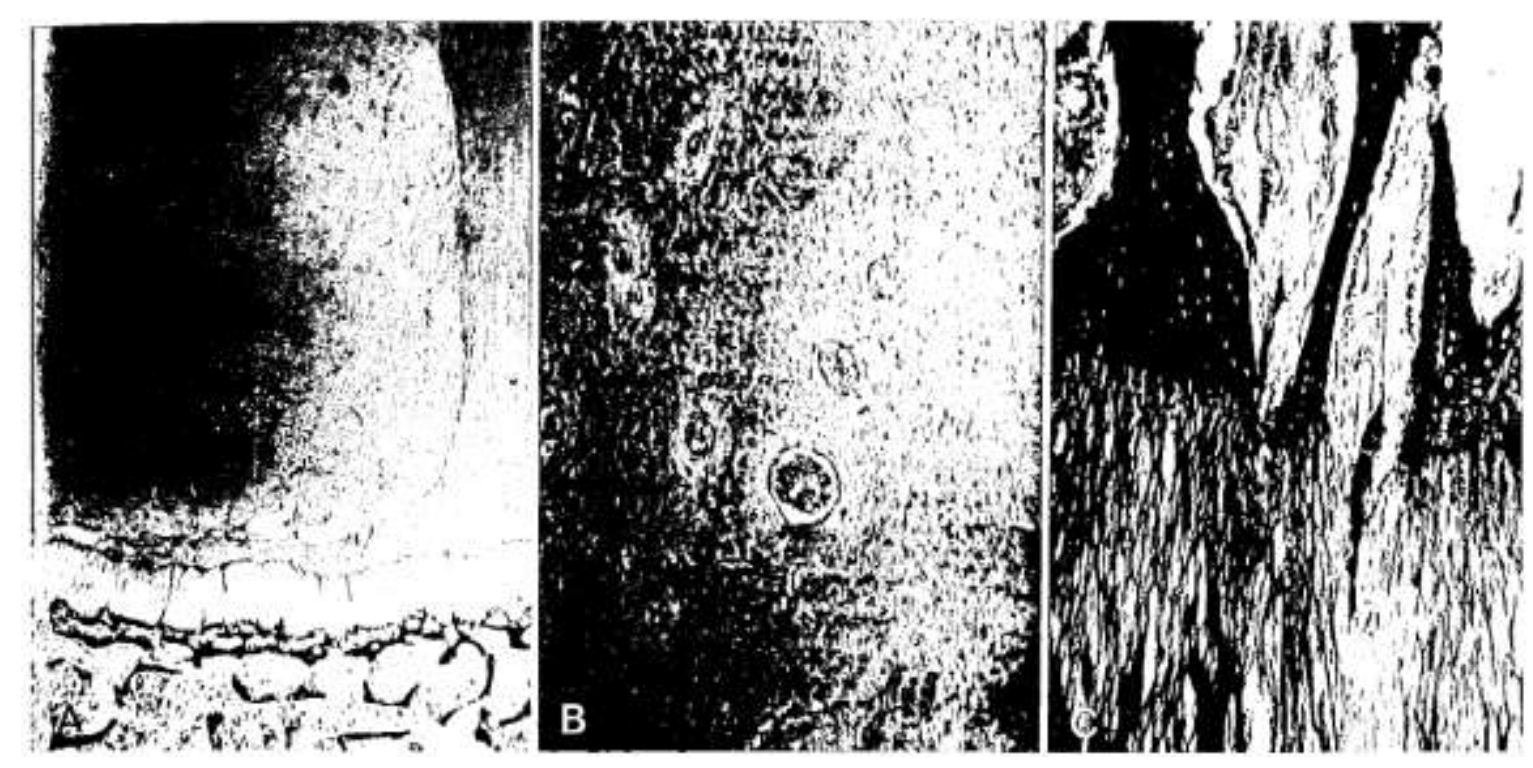

Figure 7. Histological evolution of the lengthened zone. A Fracture-haematoma. Haematoxylin-eosin ( x 4) B Granulation tissue. Haematoxylin-eosin x 4) C Desmal ossification. Masson's trichromic ( x 10) 


\begin{tabular}{|l|c|c|}
\hline \multicolumn{3}{|c|}{ Table 1. Group distribution } \\
\hline & \multicolumn{2}{|c|}{ Distraction } \\
\hline & Rate & Days \\
\hline Group A & $2 \mathrm{~mm} / \mathrm{d}$ & 10 \\
\hline Group B & $1 \mathrm{~mm} / \mathrm{d}$ & 20 \\
\hline Group C & $0,5 \mathrm{~mm} / \mathrm{d}$ & 40 \\
\hline
\end{tabular}

